\title{
DEVELOPMENT OF ARCHIMEDEAN'S PIPE-SCREW FOR THAI SAIL WINDPUMP
}

\author{
${ }^{1}$ Ronnakorn Thepwong, ${ }^{1}$ Issaree Hansacharoonroj, ${ }^{1}$ Joseph Khedari \\ ${ }^{2}$ Tawit Chitsomboon, ${ }^{3}$ Jongjit Hirunlabh and ${ }^{4}$ Sombat Teekasap \\ ${ }^{1}$ Rattanakosin College for Sustainable Energy and Environment (RCSEE), \\ Rajamangala University of Technology Rattanakosin, Puthamonthon Sai 5, \\ Salaya, Puthamonthon, Nakhon Pathom, 73170, Thailand \\ ${ }^{2}$ School of Mechanical Engineering, Suranaree University of Technology, \\ 111 University Avenue, Muang District, Nakorn Ratchasima, 30000, Thailand \\ ${ }^{3}$ Faculty of Engineering, Bangkok Thonburi University, Taweewattana, Bangkok, 10170, Thailand \\ ${ }^{4}$ Faculty of Engineering, Eastern Asia University, Bangkok, 12110, Thailand
}

Received 2014-03-05; Revised 2014-03-13; Accepted 2014-04-21

\begin{abstract}
This study describes new considerations in the design and development of Archimedean's Pipe-Screw especially for water pumping in case of low head high volume form open farm pond at Rajamangala University of Technology Rattanakosin, Thailand. The objectives of this research is to develop an Archimedean's Pipe-Screw especially for water pumping in case of low head high volume form open farm pond used for water pumping with Thai sail windmill, at any location of low wind speed of Thailand and tests the performance of an Archimedean's Pipe-Screw Model (APSM). The experimental was carried out on diameter of Archimedean's Pipe-Screw is $\phi 5 / 8$ ", the pitch Archimedean's Pipe-Screw (P) is 0.6, 0.8, 1.0, $1.2,1.4,1.6,1.8$ and $2.0 \mathrm{D}$ for angle slope of the screw with the horizontal $(\alpha)$ is $20,25,30^{\circ} \mathrm{C}$ in laboratory scale Archimedean's Pipe-Screw model. Archimedean's Pipe-Screw tests were conducted to assess the performance of characteristics of Archimedean's Pipe-Screw model. A model of pump has been manufactured; $1.0 \mathrm{~m}$ long with the blade small rubber tube was constructed. The output of the experiments recommenced for development the prototype of Archimedean's Pipe-Screw for the Thai sail wind pump. The prototype of pump has been manufactured, $4.0 \mathrm{~m}$ long, $8 \mathrm{~m}$ diameter. This wind pump has twelve triangular sails sweeping a circle of $8 \mathrm{~m}$ diameter. For the construction of this Archimedean's Pipe-Screw wind pump all efforts were made to use maximize materials and local parts available in the market for large scale of Archimedean's screw-pipe for Thai sail wind pump. The cost of material and parts is 145,000 Baht excluding the cost of machining and fabrication. Water discharge was in the range 0.005-0.081 lps. It can be seen maximum water discharge of pitch Archimedean's Pipe-Screw (P) is $1.4 \mathrm{D}$ at $80 \mathrm{rpm}$ for $\alpha=20^{\circ}$ was $0.081 \mathrm{lps}$. For the result of prototype of Archimedean's Pipe-Screw for Thai sail wind pump, it was found that the curves for the prototype of Thai sail windmill coupled to twelve Archimedean's Pipe-Screw pump of wind speed and the discharge of was increased depending on wind speed. The discharge amount varied between $9.56-38.23 \mathrm{~m} \mathrm{~m}^{3} / \mathrm{h}$ at head of $1.5 \mathrm{~m}$ in wind speeds from 1.0-5.0 m s $\mathrm{m}^{-1}$ that the overall efficiency of this windmill for water pumping was highest $(76.96 \%)$ at wind speed of $1.4 \mathrm{~m} \mathrm{~s}^{-1}$.
\end{abstract}

Keywords: Archimedean's Screw, Water Pumping, Sail Windmill, Wind Power and Wind Pump

Corresponding Author: Issaree Hansacharoonroj, Rattanakosin College for Sustainable Energy and Environment (RCSEE), Rajamangala University of Technology Rattanakosin, Puthamonthon Sai 5, Salaya, Puthamonthon, Nakhon Pathom, 73170, Thailand 


\section{INTRODUCTION}

Thailand is developing and growing very rapidly. This region's location, close to the border with the largest economy of the world, has encouraged an important industrial corridor, increasing water consumption in a zone where this resource is highly stressed and not available in large quantities. By contributing to hygiene, agricultural and public health, the availability of water constitutes an essentials factor is development. The lack of water has particularly grave consequences in Thailand, whereas a widely distributed means of water supply would contribute, moreover, to food self-sufficiency through an increase in productivity on the land and in cultivated areas. Production of water-by-water ladder pump is becoming a major issue in the entire Thailand, where people are willing to pay very high prices for this sought-after resource. The water and the energy can be considered the two basic elements supporting life and the natural environment (Chaabene et al., 2013). Energy is available in two different alternative (coal, fuel, natural gas) and renewable energy (solar, wind, hydro, wave) sources. Wind energy can be utilized for a variety of functions ranging from windmills to pumping water.

The wind energy boom includes more and more countries. The production cost at a given location depends predominantly upon the wind speed and to a lesser extent the type, size and configuration of the turbines. The placement of wind turbines in offshore locations is a relatively recent occurrence and it is an offshoot of commercial wind turbine development. The necessary conditions where offshore wind farms make sense are the combination of a strong wind resource, large areas of shallow waters located near land in an area where a demand for the electricity exists. Since installation in water is more expensive than land installation, the wind resource must be sufficient to cover the added cost (Ahilan et al., 2009). Identifying the wind field in a zone is not limited to wind energy considerations and wind field influences some other additional actions as follows: (i) Emission and dispersion of air pollutants in the atmosphere, (ii) issues related to the aerodynamic of buildings including stress and pressure distribution, heat loses and ventilation (iii) effects on transportation, such as location of airports, aerodynamic of automobiles and so forth and (iv) agricultural considerations such as soil erosion as well as the water vaporization and growth of plants (Pour et al., 2008).

Renaissance Archimedes' mechanics has been reconsidered together with a new attention to Greek-
Roman machine designs with the aim to develop an early approach for modern theory of mechanisms (Ceccarelli, 2014). One of the oldest machines still in use is the Archimedes screw, a device for lifting water for irrigation and drainage purposes. The Archimedean screw in the pumping role has been known since antiquity. It consists of an axis with helical blades, lying in a channel with a semi-circular or even closed circular cross section (Müller, 2009). The Archimedean screw can only operate through low heads, since it is mounted with its axis inclined so its lower end picks up water from the water source and the upper end discharges into a channel. Each design has an optimum angle of inclination, usually in the region of $30^{\circ}$ to $40^{\circ}$, depending on the pitch and the diameter of the internal helix. Windmills have been in use for many centuries for pumping water, United Nations Economic and Social Commission for Asia and the Pacific. According to (Major et al., 2008) studied a wind map, which has been produced for Thailand, which combines and updates the wind speed data previously available. Thailand experiences generally very low wind speeds with typically average speeds of not above $3 \mathrm{~m} \mathrm{~s}^{-1}$.

The objectives of this research is to develop an Archimedean's Pipe-Screw especially for water pumping in case of low head high volume form open farm pond used for water pumping with Thai sail windmill, at any location of low wind speed of Thailand and tests the performance of an Archimedean's Pipe-Screw Model (APSM). A model of pump has been manufactured; 1.0 meter long with the blade small rubber tube was constructed. The output of the experiments recommenced for development the prototype of Archimedean's pipe-screw for water pumping with the Thai sail windmill.

\section{MATERIALS AND METHODS}

\subsection{Materials}

Thai sail windmill Archimedean's Pipe-Screw Model (APSM) for water pumping was used as in this experimental study. The equipment were consist of rotor assembly (hub plate, tubular steel spars, support pipe and nylon rope), sail (cloth and nylon rope), power transmission (rear axle, drive shaft, universal joint and lower gear box), tail assembly (steel pipe, galvanized sheet metal and cable), turntable (steel structure and bearings), tower structure (steel pipe, plate form and foundation) and pump (Archimedean's Pipe-Screw). 


\subsection{Experimental Methods}

\subsubsection{Laboratory Scale Archimedean's Pipe- Screw Model}

Water pumping tests were conducted to assess the performance of characteristics of Archimedean's PipeScrew model. A model of pump has been manufactured, $1.0 \mathrm{~m}$ long with the blade small rubber tube was constructed Archimedean's Pipe-Screw model testing and Archimedean's Pipe-Screw (APS) are shown in Fig. 1. The diameter of shaft Archimedean's Pipe-Screw model is $15 \mathrm{~cm}$ and $1.0 \mathrm{~m}$ long.

Experiments were carried out the capacity of the screw to optimize the different parameters by very the parameter as follow: The number of blades, the size of the pipe is diameter of Archimedean's Pipe-Screw ( $\phi$ APS) is $\phi 5 / 8 "$, the Diameter of the Archimedean's Pipe-Screw (D) is the outer diameter of the APSM (diameter of shaft add diameter of Archimedean's Pipe-Screw) case and test for pipe-screw $\phi 5 / 8$ ", the pitch Archimedean's Pipe-Screw (P) is $0.6,0.8,1.0,1.2,1.4,1.6,1.8$ and $2.0 \mathrm{D}$ are shown in Fig. 2, rotation speed of the pump shaft (n), lift head, intake submergence $\%$ is $50 \%$ angle slope of the screw with the horizontal $(\alpha)$ is $20,25,30^{\circ}$.

To setup the testing of $\phi$ APS $\phi 5 / 8$ " APSM-1, APSM2, APSM-3, APSM-4, APSM-5, APSM-6, APSM-7 and APSM-8 are shown in Table 1. The rotation speed of the pump shaft APSM (n), coupled with speed adjustable motor, is 6, 15, 33, 55, 73 and $80 \mathrm{rpm}$ as shown in Table 2.

Wind velocity is measured with digital anemometer type K, J model: DA-41A, 0.4-25.0 $\mathrm{m} \mathrm{s}^{-1}$. Rotational speed of the rotor is recorded by a non-contact type digital tachometer model: UN-360P, 0.5-19999 RPM.

\subsection{Large Scale of Archimedean's Pipe-Screw for Thai Sail Wind Pump}

The characteristics of the prototype the Thai sail windmill model as shown in Table 3. The prototype of 12 blades Thai sail windmill for water pumping consists of six major components: Rotor assembly, the transmission, tail assembly, turntable, tower structure and pump. The prototype of 12 blade Thai sail windmill (12B-RMUTR) was tested at Rajamangala University of Technology Rattanakosin, 96 moo 3, Puthamonthon Sai 5, Salaya, Puthamonthon, Nakhon Pathom, 73170 Thailand as shown in Fig. 3.

Rotor assembly: The rotor assembly has been designed to face the wind ahead of the tower. It consists of a circular plate hub plate on which 12 tubular steel spars of $42.7 \mathrm{~mm}$ outer diameter are mounted, the rotor which is $8.0 \mathrm{~m}$ in diameter as shown in Fig. 9. The rotor hub is keyed to the shaft, which is about $800 \mathrm{~mm}$ away from the center of the output shaft in order to have sufficient clearance between the rotor spars and the tower. The end of the spars is connected by means of a $12 \mathrm{~mm}$ diameter nylon rope, which is stretched around the rotor circumference between the tips of each spar. The 12 support pipe of $34 \mathrm{~mm}$ outer diameter, link at the one meters of the spars from center of rotor assembly are connected through steel pipe of $42.7 \mathrm{~mm}$ outer diameter to a forward axial projection from the hub plate. This support pipe adds stiffness in the bending to spars when sails are opened to face the wind, allows the blades to feather in high winds or when overloaded. Sails: The sails, triangular in shape, are 12 in number and made of cloth. The base of sail dimension is $1.48 \times 2.96 \times 3.0 \mathrm{~m}^{2}$. On the longest side of the sail, round holes are reinforced into the rotor spars. The loose end of the sails is connected on to the rotor circumference between the tips of each spar by means of a nylon rope of $4 \mathrm{~mm}$ diameter.

Power transmission: The windmill is design uses a rigid rear axle and differential from a small car made for the upper gearbox as shown in Fig. 4. The rotor center plate is bolted to the rear axle of a small car. The rotational speed of the drive shaft will then be approximately four times higher than that of the rotor mounted on the wheel drum. The other wheel is permanently locked, resulting in a transmission ratio of about 1:4 from the horizontal to the vertical, about 2:1 for the second an automobile lower gear box could be used to decrease the rotational speed and drive to a water ladder pump. The rear axle is free to swivel about the vertical on a turntable. The whole assembly is mounted on a small platform on a turntable, a single pipe on head of tower structure. The drive shaft and the two universal joints are used to transmit the rotor power to the driven machinery. Using pipe of approximately $48.6 \mathrm{~mm}$ outer diameter can lengthen the drive shaft and the drive shaft is passed through the center of the tower structure. Tail assembly: The tail of the windmill is $5.2 \mathrm{~m}$ long and made of Galvanized sheet metal approximately $0.5 \mathrm{~mm}$ thick mounted on a framework of conduit pipes. The area of tail vane has a $6 \mathrm{~m}^{2}$ as shown in Fig. 4. Turntable: The turntable provides a rigid frame for the rotor head of windmill mechanism, rotor assembly, tail assembly, the transmission and turns over the tower pipe to orient itself towards the wind as shown in Fig. 4. Basic materials for these are angle iron, some flat iron, bolts and nuts. 
Ronnakorn Thepwong et al. / American Journal of Environmental Sciences 10 (3): 244-259, 2014

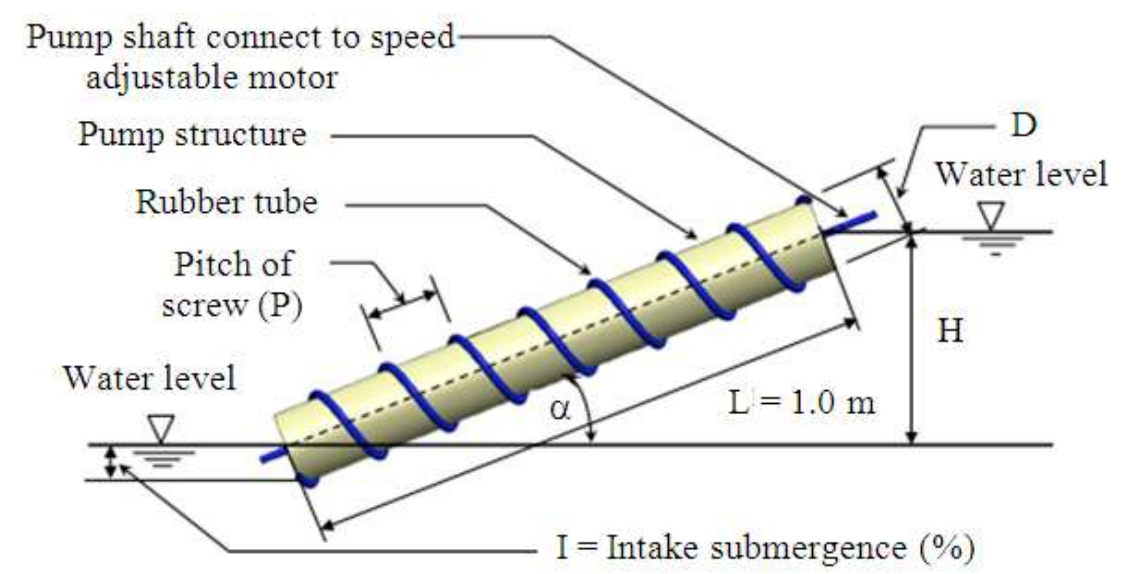

Fig. 1. Laboratory scale Archimedean's Pipe-Screw Model (APSM) for rubber tube $\phi 5 / 8$ "

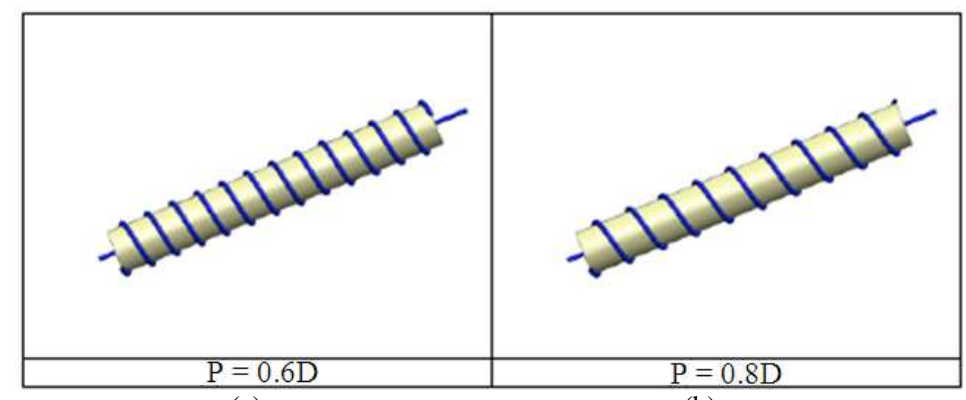

(a)

(b)

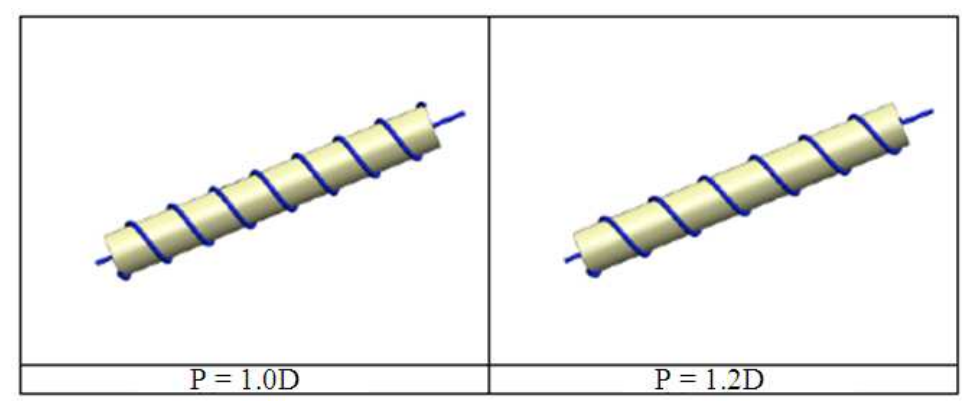

(c)

(d)

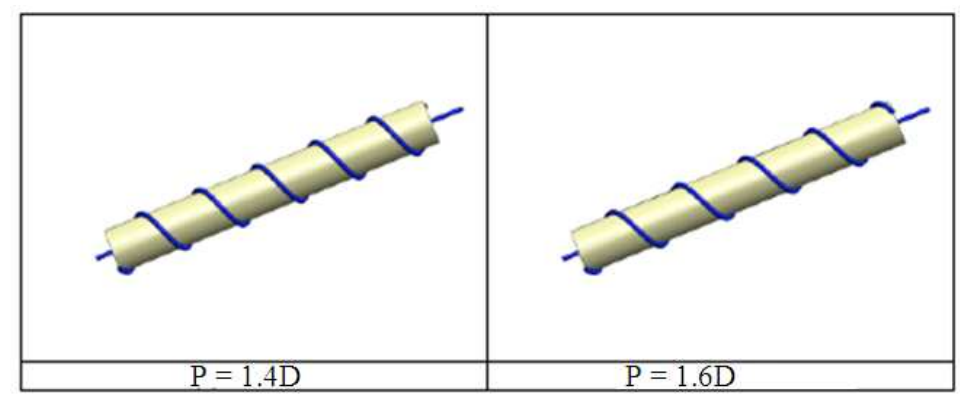

(e)

(f) 


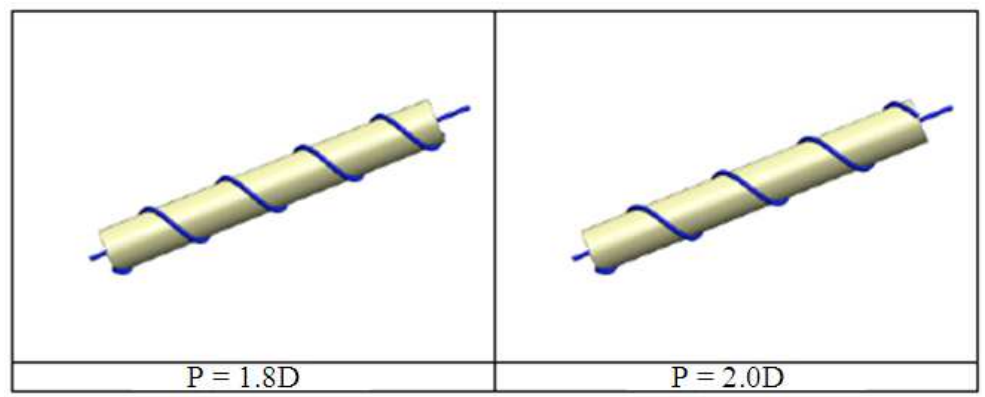

(g)

(h)

Fig. 2. Archimedean's Pipe-Screw Model rubber tube $\phi 5 / 8$ " for pitch of pipe screw 0.6D-2.0D

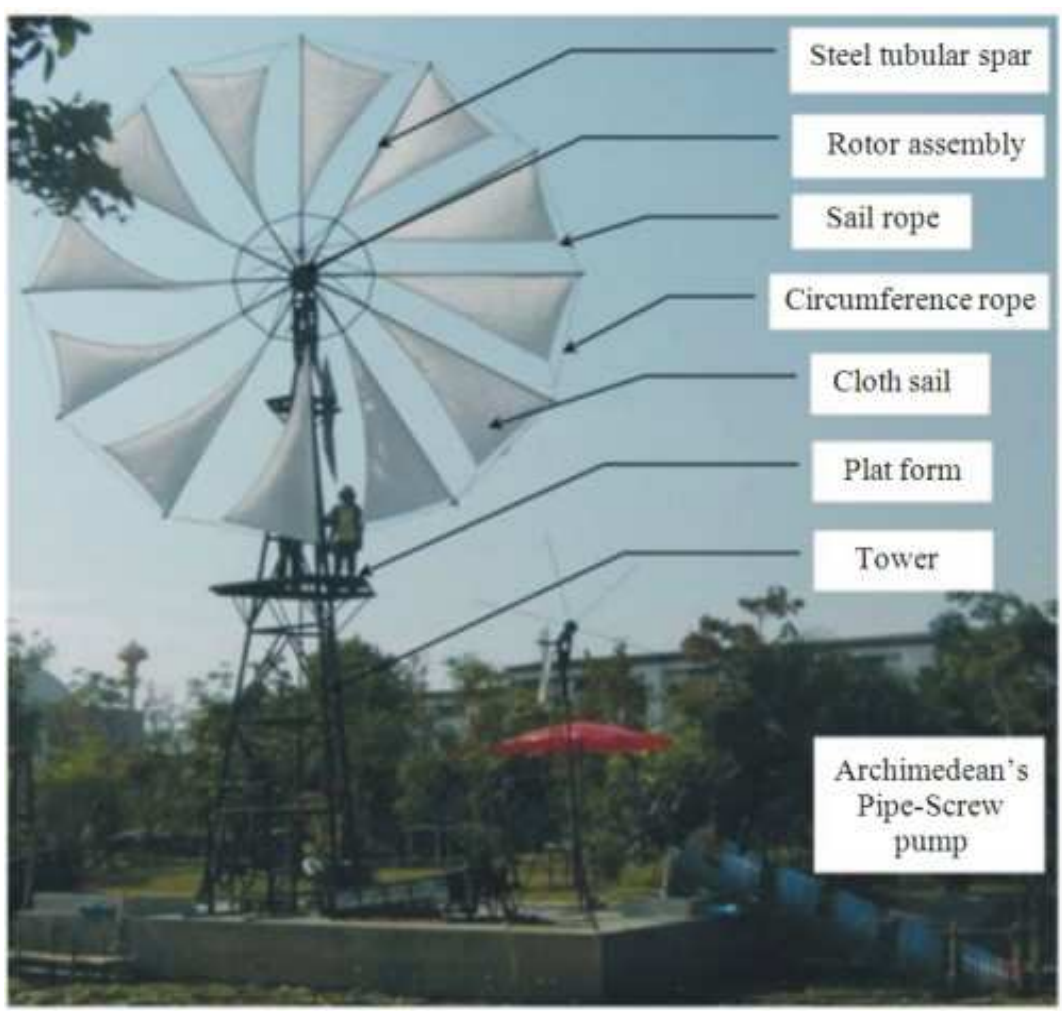

Fig. 3. The prototype of 12B-RMUTR Thai sail wind pump

Tower structure: The tower is $9.0 \mathrm{~m}$ high and is fabricated out of 48.6, 60.5 and $76.3 \mathrm{~mm}$ outer of diameter tower structure pipe. The base of tower dimension is $2.5 \times 2.5 \times 2.5 \mathrm{~m}^{2}$ as shown in Fig. 4 .

Pump: Large scale Archimedean's Pipe-Srew testing for rubber tube $\phi 2$ "used with the windmill as shown in Fig. 5-7, head of water pumping $1.5 \mathrm{~m}$. The size of Archimedean's Pipe-Screw pump is $4.0 \mathrm{~m}$ long and 0.50 m diameter.
The Archimedean's Pipe-Screw pumps coupled by horizontal drive shaft, universal joint, connect to lower gearbox of the prototype 12-blade Thai sail windmill.

\subsection{Wind Power}

Tests on the Thai sail windmill rotor model have been carried out of wind tunnel. The horizontal axis windmill rotor was away from the exit of the tunnel in all of the tests. 


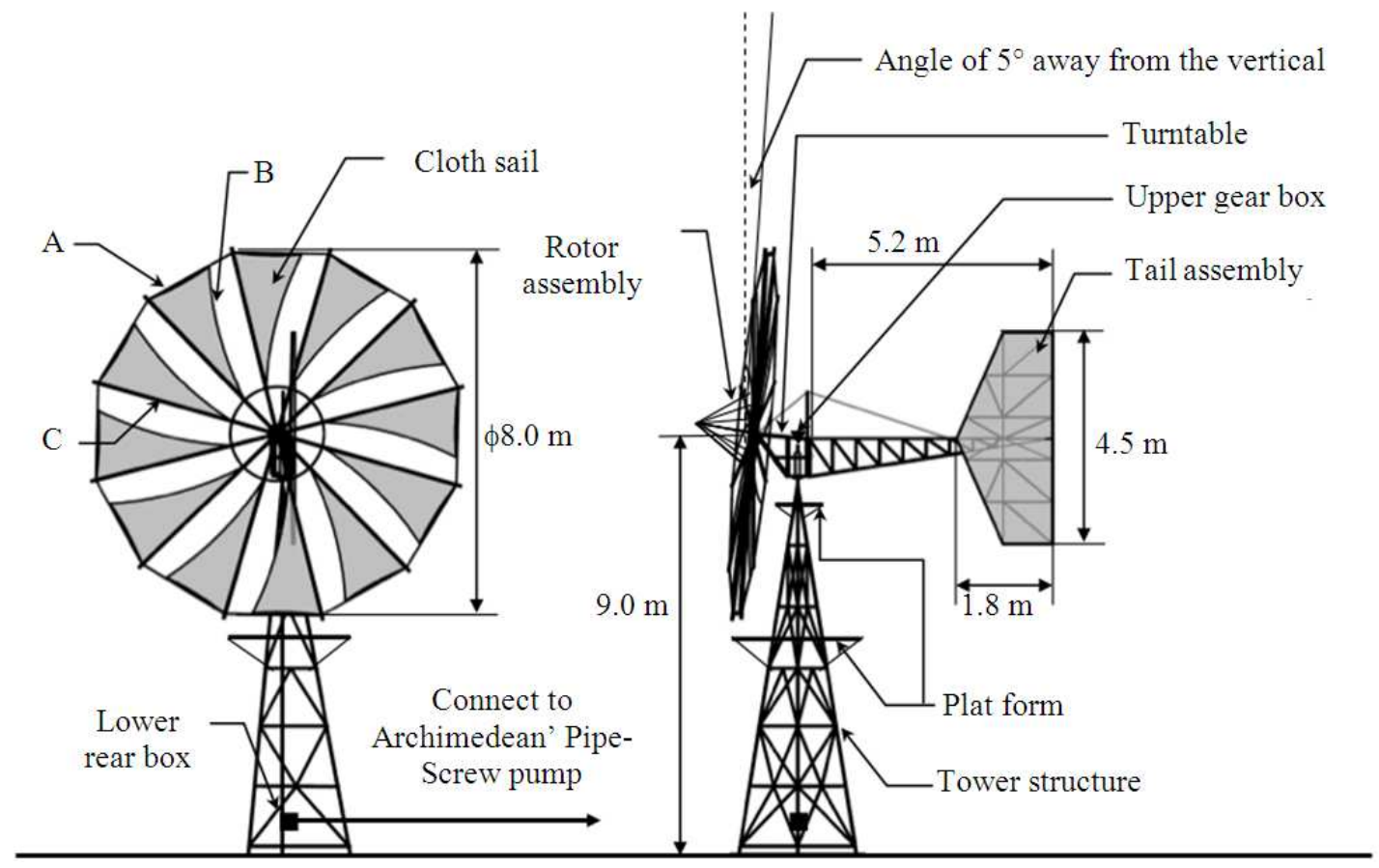

Fig. 4. Diagram of the prototype of 12 blade (12B-TSRM) Thai sail windmill rotor model for water pumping, $8 \mathrm{~m}$ diameter of Thai sail windmill having twelve triangular cloth sail

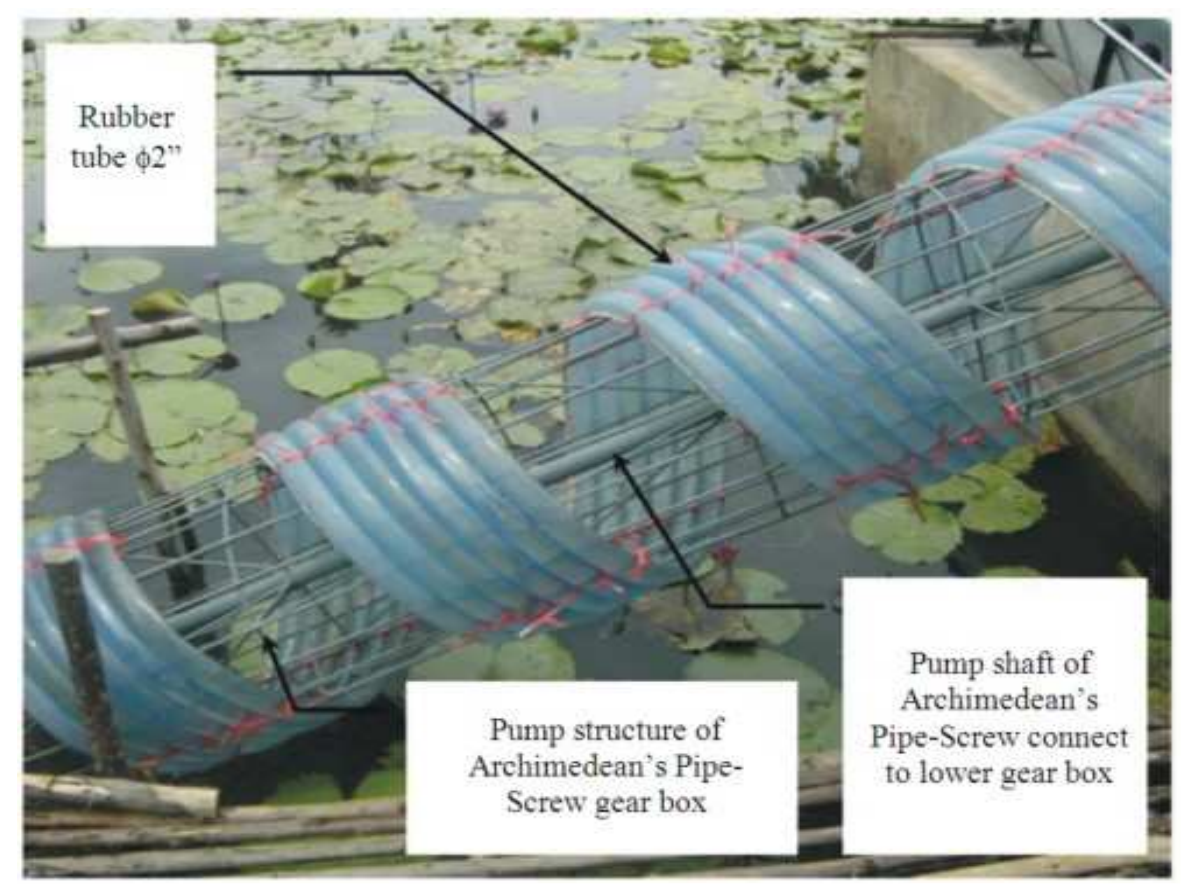

Fig. 5. The prototype of six Archimedean's Pipe-Screws (6-APS) of rubber tube $\phi 2$ " at pitch of pipe screw 1.4D 


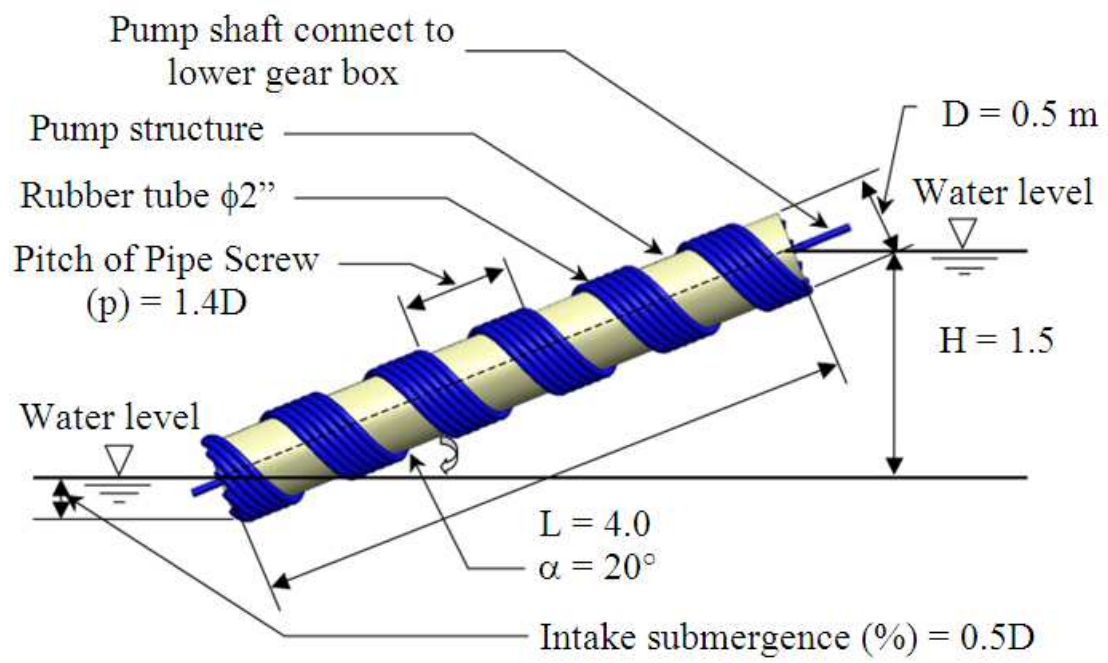

Fig. 6. Large scale Archimedean's Pipe-Screw testing for rubber tube $\phi 2 "$
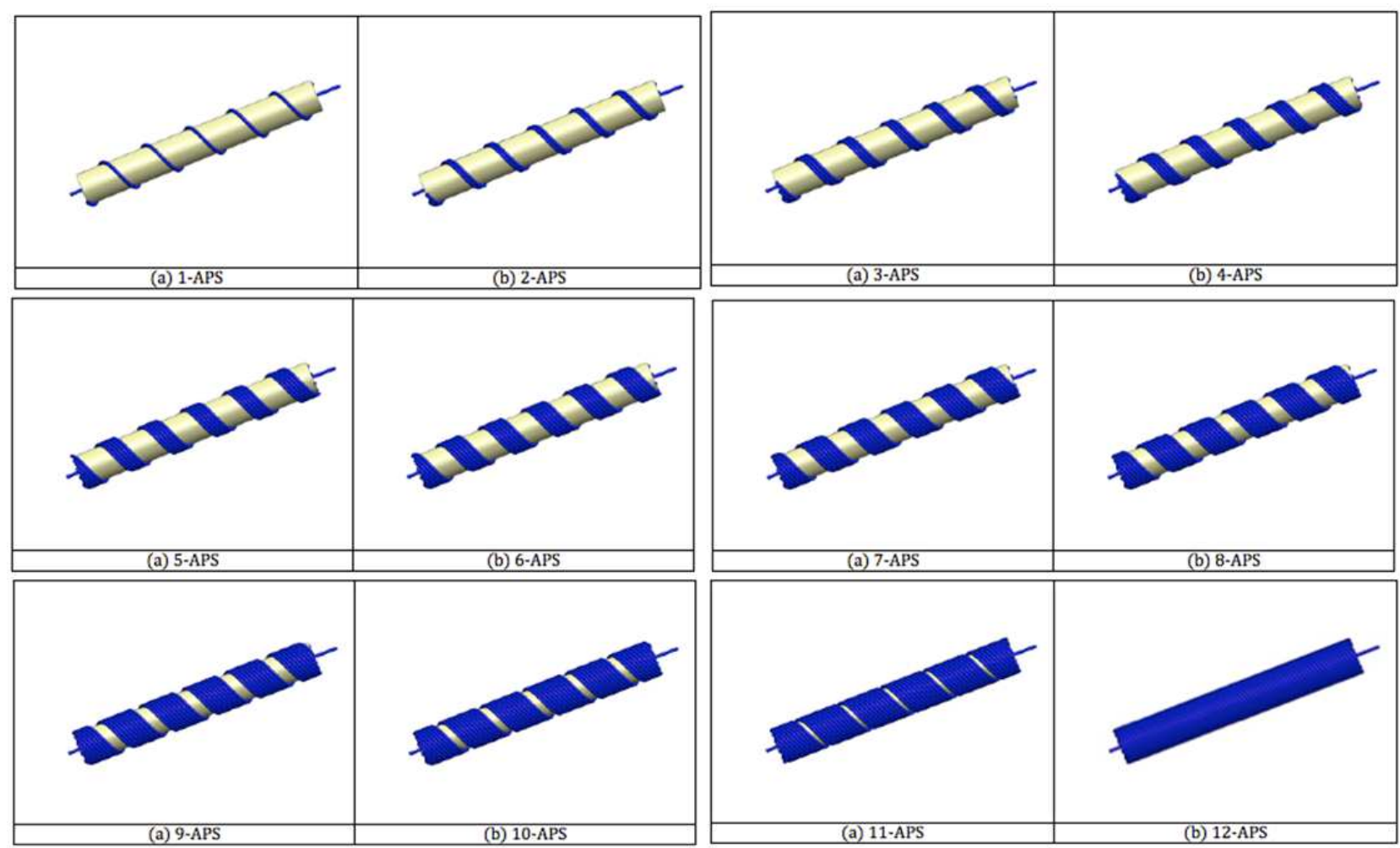

Fig. 7. The prototype of Archimedean's Pipe-Screw (APS) of rubber tube $\phi 2$ " and pitch of pipe screw 1.4D for 1 to 12-APS

Measuring the air velocity at the exit of the wind tunnel and using the relation determine the wind power input.
Thus, for a horizontal axis windmill the general equation for estimate of wind power Equation (2.1) is. 
Table 1. Testing of $\phi$ APS 5/8" diameter Archimedean's PipeScrew Model (APSM)

\begin{tabular}{lllll}
\hline & $\begin{array}{l}\text { Pitch of } \\
\text { the APS }\end{array}$ & $\mathrm{P}(\mathrm{cm})$ & $\begin{array}{l}\text { Angle } \\
\text { slope }(\alpha)\end{array}$ & $\begin{array}{l}\text { Intake } \\
\text { submergence }(\%)\end{array}$ \\
\hline APSM-1 & $0.6 \mathrm{D}$ & 11.1 & $20,25,30$ & 50 \\
APSM-2 & $0.8 \mathrm{D}$ & 14.8 & $20,25,30$ & 50 \\
APSM-3 & 1.0D & 18.5 & $20,25,30$ & 50 \\
APSM-4 & 1.2D & 22.2 & $20,25,30$ & 50 \\
APSM-5 & 1.4D & 25.9 & $20,25,30$ & 50 \\
APSM-6 & 1.6D & 29.6 & $20,25,30$ & 50 \\
APSM-7 & $1.8 \mathrm{D}$ & 33.3 & $20,25,30$ & 50 \\
APSM-8 & 2.0D & 37.0 & $20,25,30$ & 50 \\
\hline
\end{tabular}

Remark D is outer diameter of the APSM (diameter of shaft and pipe screw)

Table 2. Rotation speed of APSM

\begin{tabular}{ll}
\hline Speed & Rotating speed $\mathrm{n}(\mathrm{rpm})$ \\
\hline 1 & 6 \\
2 & 15 \\
3 & 33 \\
4 & 55 \\
5 & 73 \\
6 & 80 \\
\hline
\end{tabular}

Table 3. Characteristics of the prototype the Thai sail windmill

\begin{tabular}{llllll}
\hline Model & $\begin{array}{l}\text { Diameter } \\
(\mathrm{m})\end{array}$ & $\begin{array}{l}\text { A } \\
(\mathrm{m})\end{array}$ & $\begin{array}{l}\text { B } \\
(\mathrm{m})\end{array}$ & $\begin{array}{l}\text { C } \\
(\mathrm{m})\end{array}$ & $\begin{array}{l}\text { Rotor } \\
\text { solidity } \\
(\sigma)\end{array}$ \\
\hline 12B- Rmutr & 8.0 & 1.48 & 2.96 & 3.0 & 0.5 \\
\hline
\end{tabular}

The wind power $\left(\mathrm{P}_{\mathrm{w}}\right)$ equation:

$$
\mathrm{P}_{\mathrm{w}}=\frac{1}{2} \rho A \mathrm{~V}^{3}
$$

Where:

$\rho=$ The air density

$\mathrm{V}=$ The wind speed

$\mathrm{P}_{\mathrm{w}}=$ The power

$\mathrm{A}=$ The projected area of rotor

The hydraulic power (water power) required to life or pump water is Equation 2.2 and 2.3:

$$
\mathrm{P}_{\text {hyd }}=\mathrm{rgH}_{\mathrm{a}} \mathrm{Q}
$$

Where:

$$
\begin{aligned}
& \mathrm{r}=\text { Density of water } \\
& \mathrm{g}=\text { Acceleration due to gravity } \\
& \mathrm{H}_{\mathrm{a}}=\text { Verticle height } \\
& \mathrm{Q}=\text { Flow rate }
\end{aligned}
$$

The overall efficient $=$ water power/wind power

\section{RESULTS}

Water pumping tests were conducted to assess the performance of characteristics of Archimedean's PipeScrew Model, were carried out single Archimedean's PipeScrew (APS) blade to optimize the different parameters.

\subsection{Effect of the Pitch of Archimedean's Pipe- Screw, the Rotation Speed of the Pump Shaft (n) and Angle Slope on Water Discharge}

For the pitch of Archimedean's Pipe-Screw testing are the pitch Archimedean's Pipe-Screw (P) is 0.6, 0.8, $1.0,1.2,1.4,1.6,1.8$ and $2.0 \mathrm{D}$, average discharge of Archimedean's Pipe-Screw (APS) $\phi 5 / 8$ at $\alpha=20,25$ and $30^{\circ}$, the optimize water discharge was obtained of pitch Archimedean's Pipe-Screw (P) is 1.4D as shown in Fig. 8 and Table 4.The experiment was also monitored with respect to changes in water discharge for different designed. For the rotation speed of the pump shaft (n) of Archimedean's Pipe-Screw testing are (n) are 6, 15, 33, 55, 73 and $80 \mathrm{rpm}$ at the pitch of Archimedean's PipeScrew testing 0.6, 0.8, 1.0, 1.2, 1.4, 1.6, 1.8 and 2.0D, of Archimedean's Pipe-Screw (APS) $\phi 5 / 8$ at $\alpha=20^{\circ}, 25^{\circ}$ and $30^{\circ}$, in this results, it was found that water discharge increased with increasing the rotating speed of the pump shaft. Compared to water discharge from difference $\alpha=$ $20^{\circ}, 25^{\circ}$ and $30^{\circ}$, it was found that water discharge increasing with decreasing the angle slope $(\alpha)$. Water discharge was in the range 0.005-0.081 lps. It can be seen maximum water discharge of pitch Archimedean's Pipe-Screw (P) is 1.4D at $80 \mathrm{rpm}$ for $\alpha=20,25$ and $30^{\circ}$ were $0.081,0.079$ and 0.075 , respectively. These results indicated the pitch of Archimedean's Pipe-Screw the angle slope $(\alpha)$ had affected the water discharge.

\subsection{Field Performance of the Prototype of Archimedean's Pipe-Screw for Thai Sail Wind Pump}

Relationship between wind speed and rotating speed of Thai sail windmill 12B-TSRM rotor model in free load as shown in Fig. 9, for wind speed from 1.5$6.5 \mathrm{~m} \mathrm{~s}^{-1}$, rotating speed of a Thai sail windmill rotor assembly from $10-45 \mathrm{rpm}$ and rotating speed of drive shaft from 20-90 rpm. During tests wind direction varies continuously and the new Thai sail windmill operated correctly.

The results of relationship between rotating speed and discharge of Archimedean's Pipe-Screw pump coupled to adjustable rotating speed motor as shown in Fig. 10. 
Ronnakorn Thepwong et al. / American Journal of Environmental Sciences 10 (3): 244-259, 2014

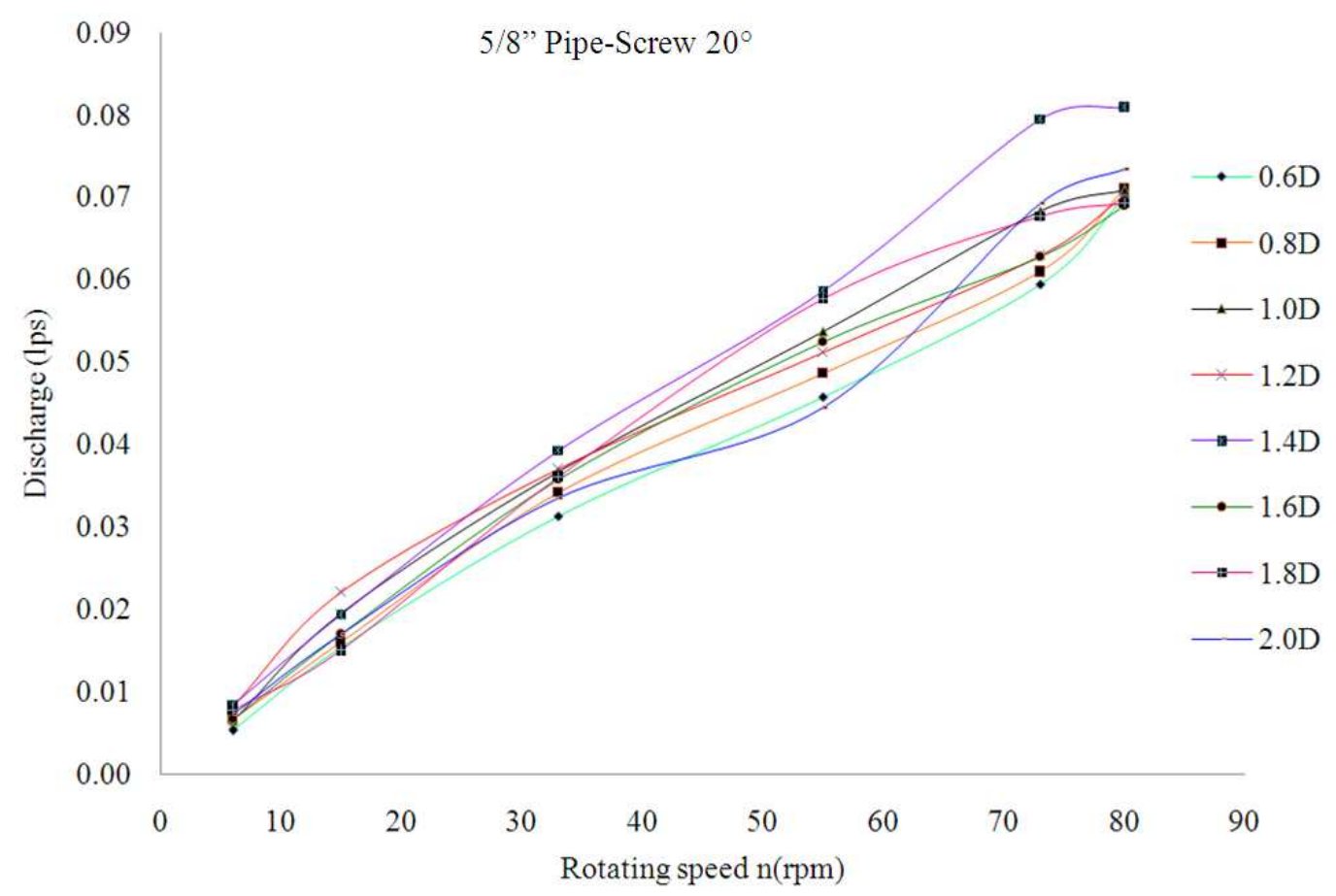

(a)

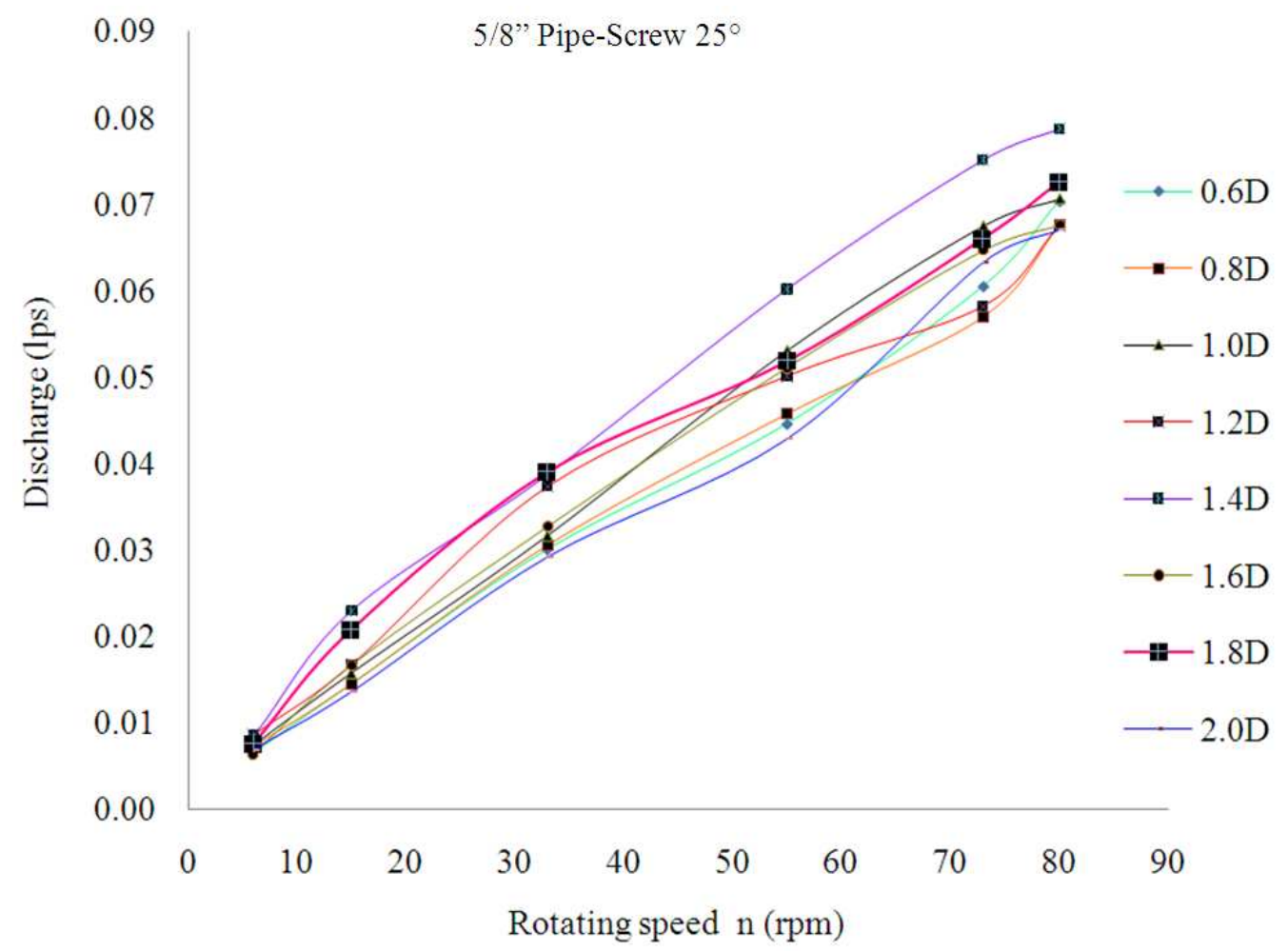

(b) 


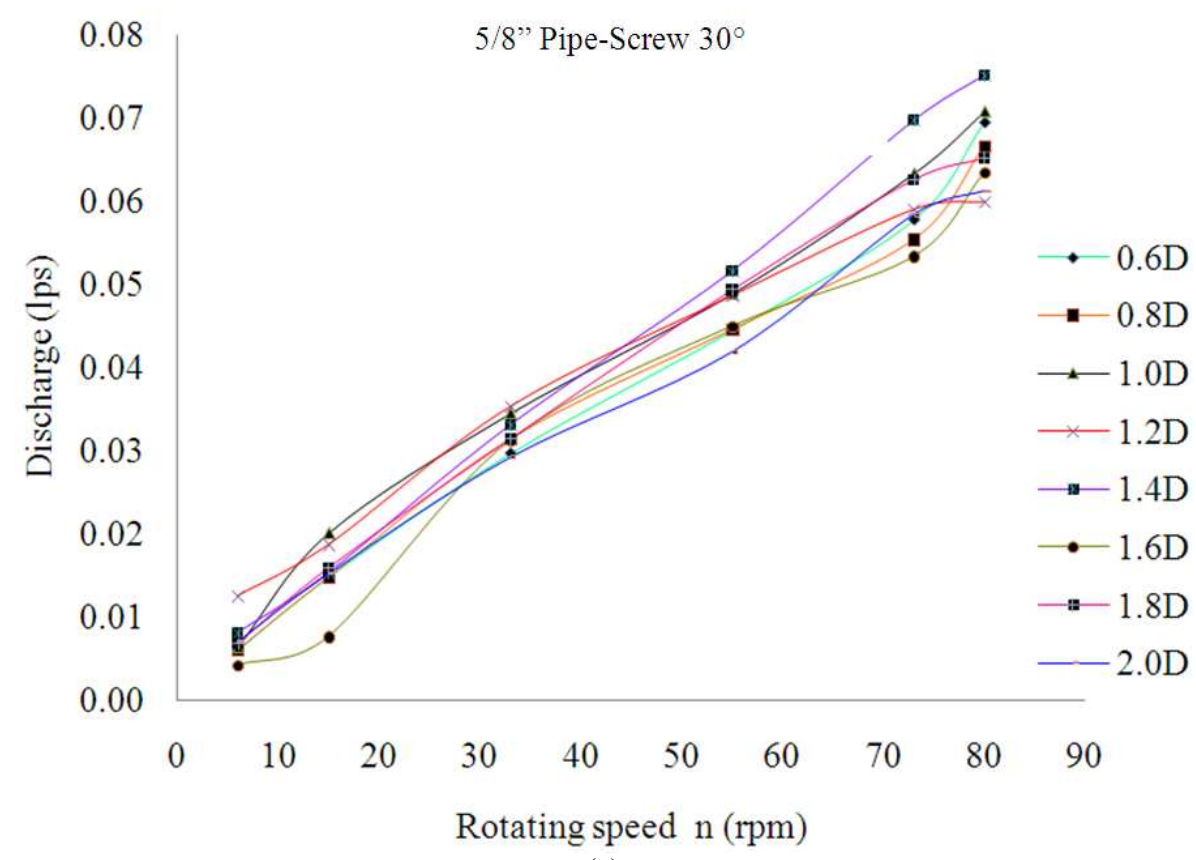

(c)

Fig. 8. Water discharge of Archimedean's Pipe-Screw (APS) $\phi 5 / 8^{\prime}$ for the pitch Archimedean's Pipe-Screw (P) is $0.6,0.8$, $1.0,1.2,1.4,1.6,1.8$ and $2.0 \mathrm{D}$ at (a) $\alpha=20^{\circ}$, (b) $\alpha=25^{\circ}$ and (c) $\alpha=30^{\circ}$

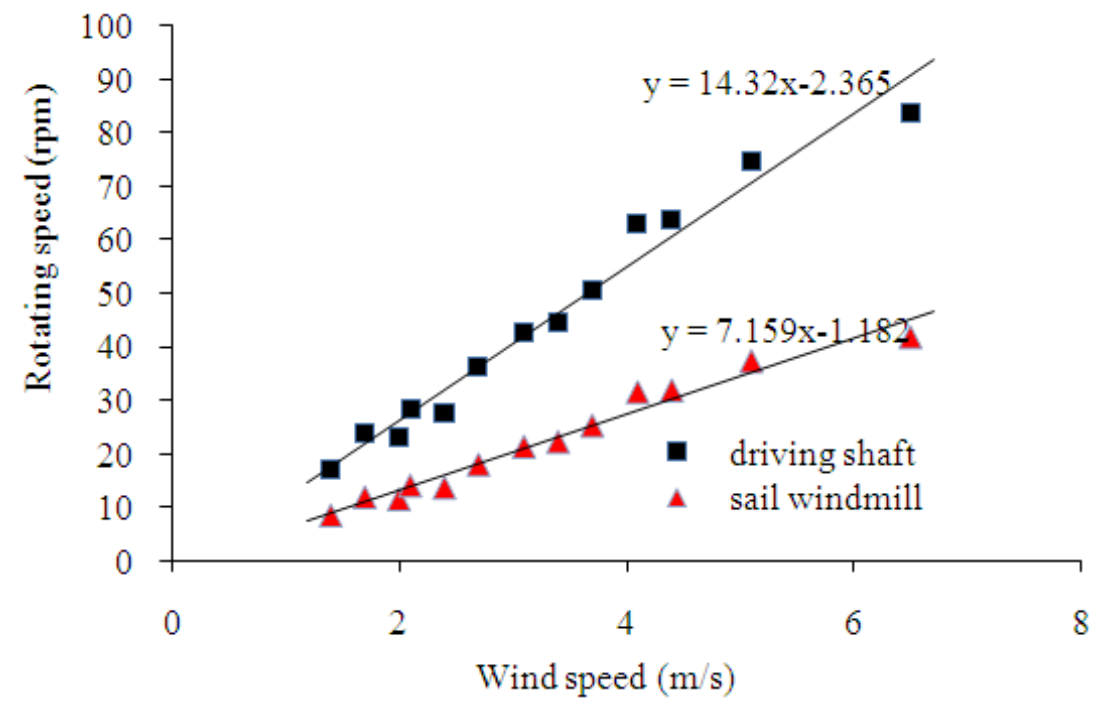

Fig. 9. Relationship between wind speed and rotating speed of the new Thai sail windmill in free load

It was found that the rotating speed of drive shaft of (i) one Archimedean's Pipe-Screw (1-APS) pump from 10.37-54.70 rpm and discharge of Archimedean's PipeScrew pump from 0.21-1.04 lps, discharge equation is $\mathrm{y}$ $=0.017 \mathrm{x}+0.0618$, (ii) two Archimedean's Pipe-Screw
(2-APS) pump from 10.27-53.90 rpm and discharge of Archimedean's Pipe-Screw pump from 0.37-2.10 lps, discharge equation is $\mathrm{y}=0.0374 \mathrm{x}-0.0097$, (iii) three Archimedean's Pipe-Screw (3-APS) pump from 10.07$53.72 \mathrm{rpm}$ and discharge of Archimedean's Pipe-Screw 
pump from 0.51-2.87 lps, discharge equation is $\mathrm{y}=$ 0.0516x-0.0197, (iv) four Archimedean's Pipe-Screw (4-APS) pump from 9.87-53.53 rpm and discharge of Archimedean's Pipe-Screw pump from 0.82-4.52 lps, discharge equation is $\mathrm{y}=0.0833 \mathrm{x}-0.0544$, (v) five Archimedean's Pipe-Screw (5-APS) pump from 9.70$53.43 \mathrm{rpm}$ and discharge of Archimedean's PipeScrew pump from 0.94-5.26 lps, discharge equation is $\mathrm{y}=0.0981 \mathrm{x}-0.0108$, (vi) six Archimedean's PipeScrew (6-APS) pump from 9.53-53.33 rpm and discharge of Archimedean's Pipe-Screw pump from 1.11-6.29 lps, discharge equation is $\mathrm{y}=$ $0.1195 x+0.075$. (vii) seven Archimedean's PipeScrew (7-APS) pump from 9.35-53.10 rpm and discharge of Archimedean's Pipe-Screw pump from 1.27-7.51 lps, discharge equation is $\mathrm{y}=0.1469 \mathrm{x}-$ 0.0273, (viii) eight Archimedean's Pipe-Screw (8APS) pump from 9.17-52.87 rpm and discharge of Archimedean's Pipe-Screw pump from 1.49-9.33 lps, discharge equation is $\mathrm{y}=0.1895 \mathrm{x}-0.238$, (viiii) nine Archimedean's Pipe-Screw (9-APS) pump from 8.30$52.03 \mathrm{rpm}$ and discharge of Archimedean's PipeScrew pump from 1.60-11.85 lps, discharge equation is $\mathrm{y}=0.2319 \mathrm{x}-0.4131$, $(\mathrm{x})$ ten Archimedean's PipeScrew (10-APS) pump from 8.20-54.70 rpm and discharge of Archimedean's Pipe-Screw pump from 1.74-13.46 lps, discharge equation is $\mathrm{y}=0.2578 \mathrm{x}-$
0.3881, (xi) eleven Archimedean's Pipe-Screw (11APS) pump from 7.80-50.87 rpm and discharge of Archimedean's Pipe-Screw pump from 1.67-13.95 lps, discharge equation is $\mathrm{y}=0.2841 \mathrm{x}-0.3863$ and (xii) twelve Archimedean's Pipe-Screw (12-APS) pump from 11.47-48.37 rpm and discharge of Archimedean's Pipe-Screw pump from 3.82-14.53 lps, discharge equation is $\mathrm{y}=0.2897 \mathrm{x}+0.2272$.

It can be seen from Fig. 10 that 12-APS has a highest the rotating speed. It provides an upper bound for the amount of water that can be pumped higher than lower-APS.

According to relationship between wind speed and rotating speed of Thai sail windmill coupled to twelve Archimedean's Pipe-Screw (12-APS) pump is equation $\mathrm{y}=6.8731 \mathrm{x}+1.5082$ as shown in Fig. 11, wind speed from 1.0-5.1 $\mathrm{m} \mathrm{s}^{-1}$, rotating speed of drive shaft of twelve Archimedean's Pipe-Screw (12-APS) pump from 8.56-37.7 rpm as shown in Table 5. Performance curve of the prototype of Thai sail windmill 12B-T0 of wind speed and discharge of Archimedean's Pipe-Screw pump are shown in Fig. 12 and 14. It can be observed that the discharge of twelve Archimedean's Pipe-Screw (12-APS) pump was increased depending on wind speed. The discharge amount varied between $9.56-38.23 \mathrm{~m}^{3} / \mathrm{hr}$ at wind speed from 1.0-5.0 $\mathrm{m} \mathrm{s}^{-1}$.

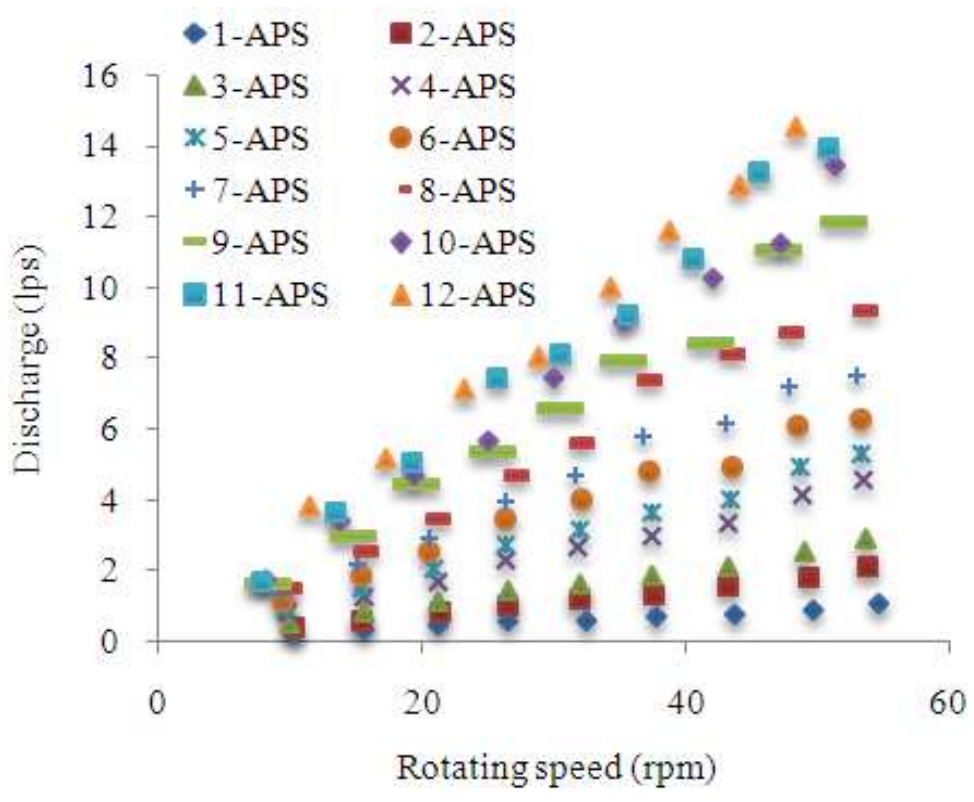

Fig. 10. Relationship between rotating speed and discharge of four Archimedean's Pipe-Screw (1-12-APS) pump coupled to adjustable rotating speed motor for $1.4 \mathrm{D}$ of the pitch Archimedean's Pipe-Screw and $\alpha=20^{\circ}$ 


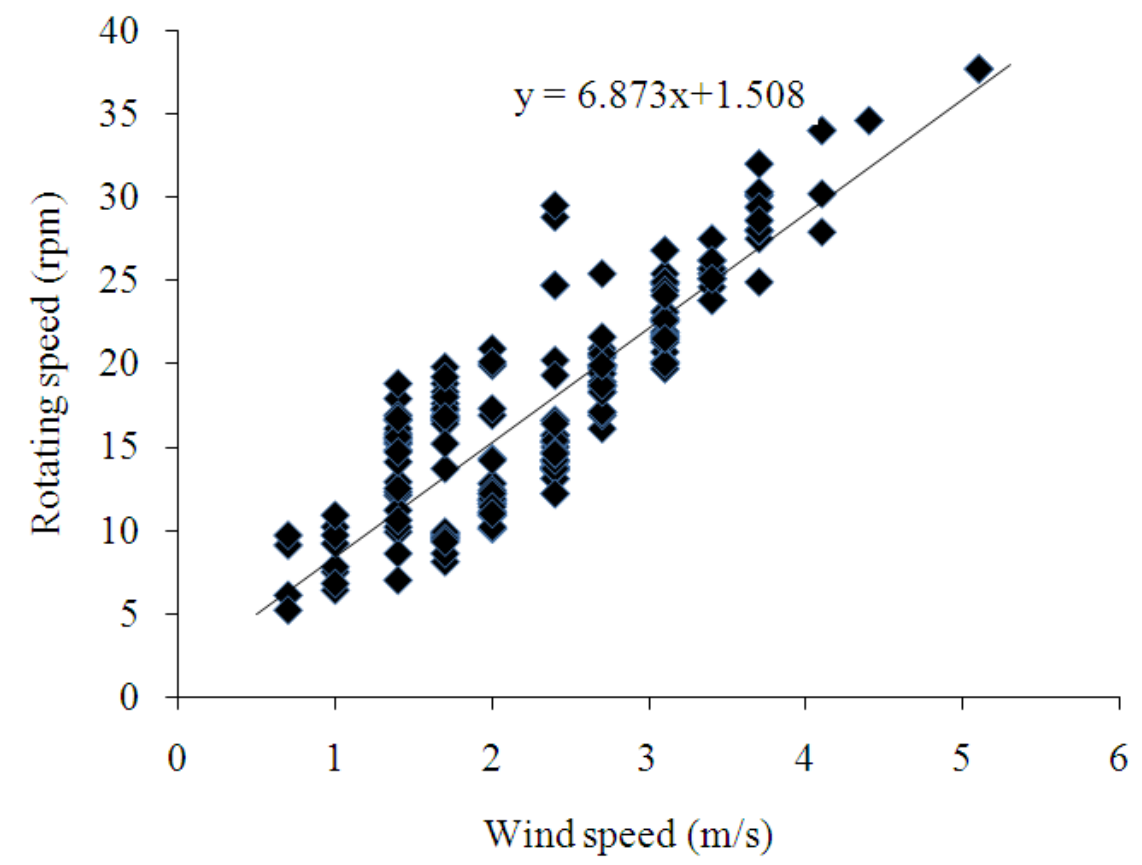

Fig. 11. Relationship between wind speed and rotating speed of the new Thai sail windmill coupled to twelve Archimedean's Pipe-Screw (12-APS) pump for 1.4 D of the pitch Archimedean's Pipe-Screw and $\alpha=20^{\circ}$

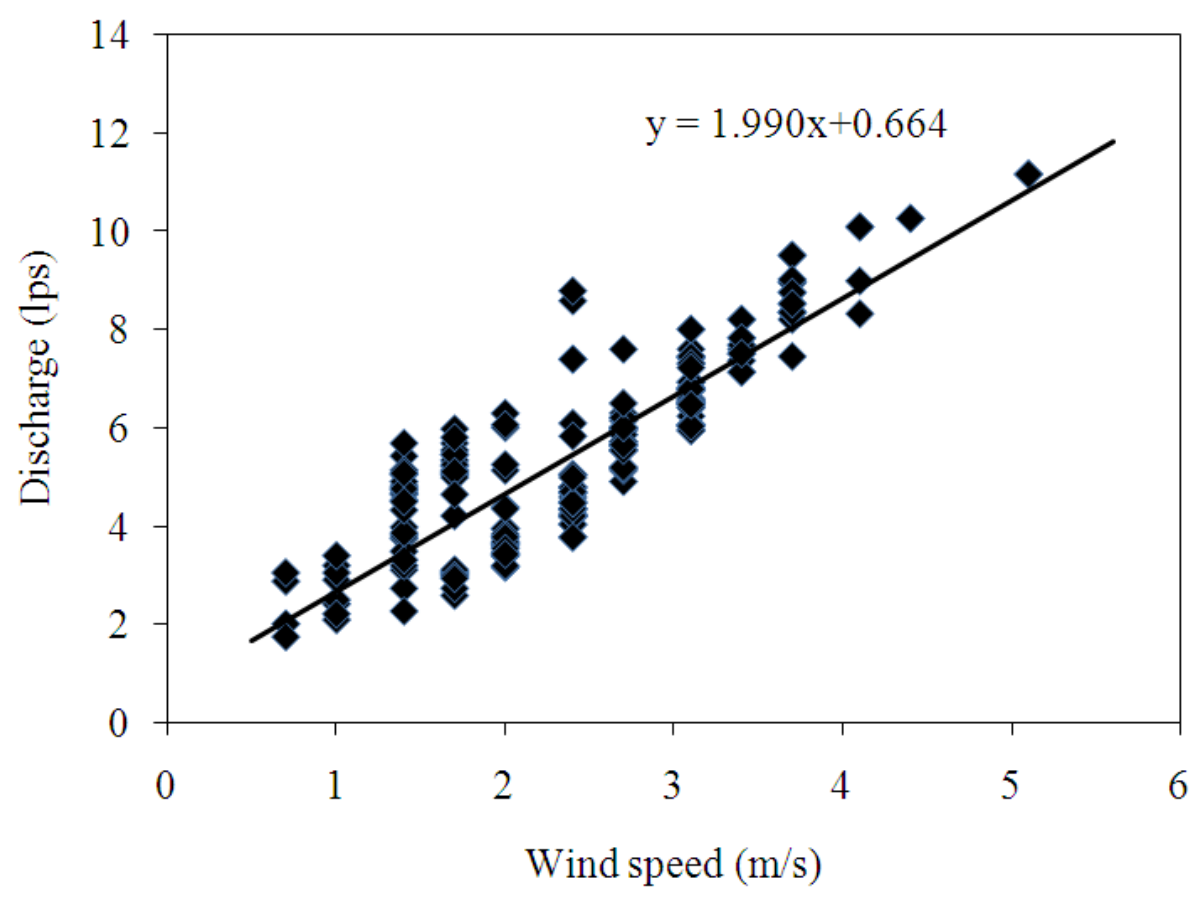

Fig. 12. Performance curve of wind speed and discharge (lps) of twelve Archimedean's Pipe-Screw (12-APS) pump coupled by the new Thai sail windmill for 1.4 D of the pitch Archimedean's Pipe-Screw and $\alpha=20^{\circ}$ 


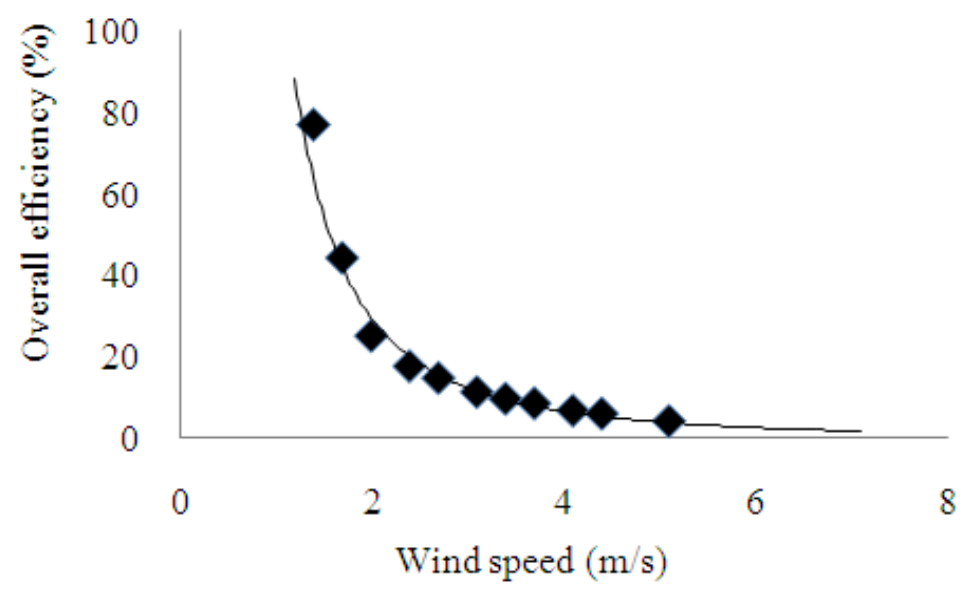

Fig. 13. Relationship between wind speed and overall efficiency of twelve Archimedean's Pipe-Screw (12-APS) pump coupled by the new Thai sail windmill for 1.4 D of the pitch Archimedean's Pipe-Screw and $\alpha=20^{\circ}$

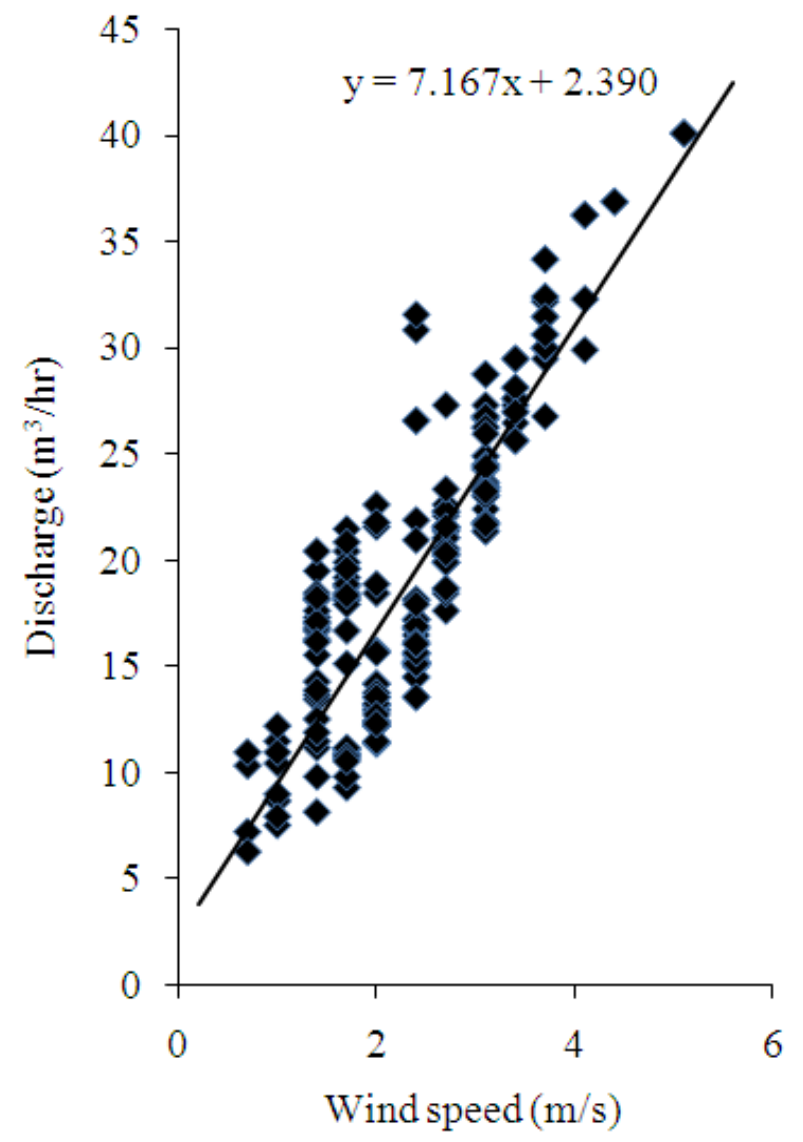

Fig. 14. Performance curve of wind speed and discharge $\left(\mathrm{m}^{3} / \mathrm{h}\right)$ of twelve Archimedean's Pipe-Screw (12-APS) pump coupled by the new Thai sail windmill for 1.4 D of the pitch Archimedean's Pipe-Screw and $\alpha=20^{\circ}$ 
Table 4. Water discharge of Archimedean's Pipe-Screw (APS) $\phi 5 / 8^{\prime}$ for the pitch Archimedean's Pipe-Screw (P) is 0.6, 0.8, $1.0,1.2,1.4,1.6,1.8$ and $2.0 \mathrm{D}$ at (a) $\alpha=20^{\circ}$, (b) $\alpha=25^{\circ}$ and (c) $\alpha=30^{\circ}$

\begin{tabular}{|c|c|c|c|c|c|c|c|c|}
\hline \multirow[b]{2}{*}{$\alpha=20^{\circ}$ speed } & \multicolumn{8}{|c|}{ Water discharge of $5 / 8$ " in pipe screw model (lps) } \\
\hline & $0.6 \mathrm{D}$ & $0.8 \mathrm{D}$ & $1.0 \mathrm{D}$ & $1.2 \mathrm{D}$ & $1.4 \mathrm{D}$ & $1.6 \mathrm{D}$ & $1.8 \mathrm{D}$ & $2.0 \mathrm{D}$ \\
\hline 6 & 0.005 & 0.007 & 0.007 & 0.008 & 0.008 & 0.007 & 0.008 & 0.007 \\
\hline 15 & 0.015 & 0.016 & 0.020 & 0.022 & 0.019 & 0.017 & 0.015 & 0.017 \\
\hline 33 & 0.031 & 0.034 & 0.037 & 0.037 & 0.039 & 0.036 & 0.036 & 0.034 \\
\hline 55 & 0.046 & 0.049 & 0.054 & 0.051 & 0.059 & 0.052 & 0.058 & 0.045 \\
\hline 73 & 0.059 & 0.061 & 0.068 & 0.063 & 0.080 & 0.063 & 0.068 & 0.069 \\
\hline 80 & 0.070 & 0.071 & 0.071 & 0.070 & 0.081 & 0.069 & 0.069 & 0.073 \\
\hline$\alpha=25^{\circ}$ speed & $0.6 \mathrm{D}$ & $0.8 \mathrm{D}$ & $1.0 \mathrm{D}$ & $1.2 \mathrm{D}$ & $1.4 \mathrm{D}$ & $1.6 \mathrm{D}$ & $1.8 \mathrm{D}$ & $2.0 \mathrm{D}$ \\
\hline 6 & 0.007 & 0.007 & 0.007 & 0.009 & 0.008 & 0.006 & 0.008 & 0.007 \\
\hline 15 & 0.015 & 0.015 & 0.016 & 0.017 & 0.023 & 0.017 & 0.021 & 0.014 \\
\hline 33 & 0.030 & 0.031 & 0.032 & 0.037 & 0.039 & 0.033 & 0.039 & 0.029 \\
\hline 55 & 0.045 & 0.046 & 0.053 & 0.050 & 0.060 & 0.051 & 0.052 & 0.043 \\
\hline 73 & 0.061 & 0.057 & 0.068 & 0.058 & 0.075 & 0.065 & 0.066 & 0.063 \\
\hline 80 & 0.070 & 0.068 & 0.071 & 0.068 & 0.079 & 0.068 & 0.073 & 0.067 \\
\hline$\alpha=30^{\circ}$ speed & $0.6 \mathrm{D}$ & $0.8 \mathrm{D}$ & $1.0 \mathrm{D}$ & $1.2 \mathrm{D}$ & $1.4 \mathrm{D}$ & $1.6 \mathrm{D}$ & $1.8 \mathrm{D}$ & $2.0 \mathrm{D}$ \\
\hline 6 & 0.006 & 0.006 & 0.006 & 0.013 & 0.008 & 0.004 & 0.007 & 0.007 \\
\hline 15 & 0.015 & 0.015 & 0.020 & 0.019 & 0.015 & 0.008 & 0.016 & 0.015 \\
\hline 33 & 0.030 & 0.031 & 0.034 & 0.035 & 0.033 & 0.031 & 0.031 & 0.029 \\
\hline 55 & 0.044 & 0.045 & 0.049 & 0.049 & 0.052 & 0.045 & 0.049 & 0.042 \\
\hline 73 & 0.058 & 0.055 & 0.063 & 0.059 & 0.070 & 0.053 & 0.063 & 0.058 \\
\hline 80 & 0.069 & 0.067 & 0.071 & 0.060 & 0.075 & 0.063 & 0.065 & 0.061 \\
\hline
\end{tabular}

Table 5. Results of wind speed and discharge $\left(\mathrm{m}^{3} / \mathrm{h}\right)$ of twelve Archimedean's pipe screw (12-APS) pump coupled by the new Thai sail windmill for $1.4 \mathrm{D}$ of the pitch Archimedean's pipe-screw and $\alpha=20^{\circ}$

\begin{tabular}{llllcrr}
\hline $\begin{array}{l}\text { Wind speed } \\
(\mathrm{m} / \mathrm{s})\end{array}$ & $\begin{array}{l}\text { Average rotating } \\
\text { speed }(\mathrm{rpm})\end{array}$ & $\begin{array}{l}\text { Discharge } \\
\mathrm{Q}\left(\mathrm{m}^{3} / \mathrm{hr}\right)\end{array}$ & $\begin{array}{l}\text { Discharge } \\
\mathrm{Q}(\mathrm{lps})\end{array}$ & $\begin{array}{l}\text { Water power } \\
(\mathrm{W})\end{array}$ & $\begin{array}{l}\text { Wind power } \\
(\mathrm{W})\end{array}$ & $\begin{array}{l}\text { The overall } \\
\text { efficiency }\end{array}$ \\
\hline 1.40 & 13.80 & 15.21 & 4.23 & 62.12 & 80.72 & 76.96 \\
1.70 & 14.23 & 15.66 & 4.35 & 63.95 & 144.53 & 44.25 \\
2.00 & 13.10 & 14.48 & 4.02 & 59.12 & 235.34 & 25.12 \\
2.40 & 16.10 & 17.60 & 4.89 & 71.88 & 406.66 & 17.68 \\
2.70 & 19.36 & 21.00 & 5.83 & 85.77 & 579.02 & 14.81 \\
3.10 & 22.53 & 24.31 & 6.75 & 99.28 & 876.37 & 11.33 \\
3.40 & 25.55 & 27.46 & 7.63 & 112.14 & 1156.21 & 9.70 \\
3.70 & 29.08 & 31.14 & 8.65 & 127.14 & 1490.07 & 8.53 \\
4.10 & 31.53 & 33.69 & 9.36 & 137.58 & 2027.46 & 6.79 \\
4.40 & 34.60 & 36.90 & 10.25 & 150.67 & 2505.87 & 6.01 \\
\hline
\end{tabular}

Table 6. A list of components used in the prototype and cost of the new generation of Thai sail windmill

\begin{tabular}{ll}
\hline Components & Baht \\
\hline Rotor assembly: Hub plate, tubular steel spars, support pipe, nylon rope & 12,000 \\
Sail: Cloth, nylon rope & 3,000 \\
Power transmission: Rear axle, drive shaft, universal joint, lower gear box & 9,000 \\
Tail assembly: Steel pipe, galvanized sheet metal, cable & 10,000 \\
Turntable: Steel structure, bearings & 6,000 \\
Tower structure: Steel pipe, plat form, foundation & 90,000 \\
Pump: Archimedean's pipe-screw & 15,000 \\
Total & 145,000 \\
\hline
\end{tabular}


In particular, wind speed and the overall efficiency of Thai sail windmill coupled to twelve Archimedean's Pipe-Screw (12-APS) pump are shown in Fig. 13 and Table 5. It was found that the overall efficiency of this windmill for water pumping was highest $(76.96 \%)$ at wind speed of $1.4 \mathrm{~m} \mathrm{~s}^{-1}$ and the value would decrease as the wind speed increased.

\subsection{Cost of Windmill}

An estimate of parts used for construction of the prototype of the new generation of Thai sail windmill is given in Table 6 the total cost of windmill is 145,000 Baht.

The cost is quite reasonable and could be acceptable by farmers. Implementing the use of our new windmill would help improve farmer productivity.

\section{DISCUSSION}

In this study, robust design, which was relatively simple to construct, was in essence the main criteria for the design improvement and development of Archimedean's pipe-screw for 12B-RMUTR Thai sail wind pump. Tests were also performed on an Archimedean's Pipe-Screw to find the best model for water pumping. The prototype of Archimedean's PipeScrew for Thai sail wind pump consists of six major components: Rotor assembly, the transmission, tail assembly, turntable, tower structure and pump. A large windmill and Archimedean's Pipe-Screw was then constructed and tested. The overall size of the windmill and its tower structure height of $9.0 \mathrm{~m}$, the base of tower dimension is $2.5 \times 2.5 \times 2.5 \mathrm{~m}^{2}$, the rotor that is $8.0 \mathrm{~m}$ in diameter. These specifications ensure that sails have a high starting torque and are able to be coupled to water pumping applications. The windmills designed for multidirectional winds have a tail vane attached to the turntable. The overall size of the Archimedean's PipeScrew structure long of $4.0 \mathrm{~m}$ and which is $0.5 \mathrm{~m}$ in diameter. These specifications ensure that pump can be coupled to water pumping applications which 12BRMUTR Thai sail windmill. The Archimedean's PipeScrew designed for simple, cheap and easy to use. All materials used had fit for the purpose intended with the main criteria being robustness from loads imposed from wind and other forces. The results provided as a performance of water pumping enables suitable applications to be suggested.

The wind pumping devices described here have been designed using solutions of technicality. An advantage of these devices is their low cost (The cost of material and the parts is 145,000 Baht) excluding the cost of machining and fabrication. The pitch of Archimedean's Pipe-Screw, angle slope $(\alpha)$ and the rotation speed of the pump shaft (n) were necessary for the Archimedean's Pipe-Screw water pumping. Significant differences angle slope have been presented. Twelve Archimedean's PipeScrew (12-APS) pump coupled by the new Thai sail windmill for pitch of pipe screw 1.4 D has been showed to work better than lower-APS (1 to 11-APS) in severe water discharge. It was found that the overall efficiency of this windmill for water pumping was highest $(76.96 \%)$ at wind speed of $1.4 \mathrm{~m} \mathrm{~s}^{-1}$. Archimedean's Pipe-Screw water pumping seems more advantageous than the water ladder pump. The strength of the Archimedean's Pipe-Screw water pumping concept is possibility to keep the structure simple. Another advantage is its expected low need of maintenance. On the other hand, Rojas-Sola et al. (2006) had study of windmills it was found that the wind seed for the southern windmill (Collado) to work at an optimum level was around $8.40 \mathrm{~m} \mathrm{~s}^{-1}$, which have a rotation speed of runner of $60 \mathrm{rpm}$; however, for the Manchegan windmill (Infante) such a wind speed was too high, as the runner would turn at $115 \mathrm{rpm}$, too fast to produce fine uniform flour. The maximum permitted wind speed was around 7 $\mathrm{m} \mathrm{s}^{-1}$, which in itself was a high speed to produce high quality flour which the our study shows us that there are wind speed was too low 1.4-4.4 $\mathrm{m} \mathrm{s}^{-1}$ as shown in Table 5, which gave a average rotating speed of 13.8-34.6 rpm, as the wind was sufficient to obtained the optimum rotation speed of to produce a water pumping. Wind has considerable amount of kinetic energy when blowing at high wind speeds. This kinetic Energy when passing through the blades of the wind turbines is converted into mechanical energy and rotates the wind blades and the connected generator, thereby producing electricity. A wind turbine primarily consists of a main tower, blades, nacelle, hub, main shaft, gearbox, bearing and housing, brake and generator. The main tower is 50-100 m high. Generally, three blades made up of Fiber Reinforced Polyester are mounted on the hub, while in the nacelle the major parts are housed (Ahilan et al., 2009). One of the principal differences between the wind turbine and windmill water pumping is to be found in the high wind speed and low wind speed, respectively. Therefore, The present results in practice suggest that the use of Archimedean's Pipe-Screw water pumping Thai sail windmill is advantage other type, which is operated on low wind speed, that it is suitable in Thailand. 
The wind pumping devices described here have been designed using solutions of technicality. An advantage of these devices is their low cost (The cost of material and the parts is 145,000 Baht) excluding the cost of machining and fabrication. The pitch of Archimedean's Pipe-Screw, angle slope $(\alpha)$ and the rotation speed of the pump shaft $(n)$ were necessary for the Archimedean's Pipe-Screw water pumping. Significant differences angle slope have been presented. Twelve Archimedean's Pipe-Screw (12APS) pump coupled by the new Thai sail windmill for pitch of pipe screw 1.4 D has been showed to work better than lower-APS (1 to 11-APS) in severe water discharge. It was found that the overall efficiency of this windmill for water pumping was highest $(76.96 \%)$ at wind speed of $1.4 \mathrm{~m} \mathrm{~s}^{-1}$. Archimedean's Pipe-Screw water pumping seems more advantageous than the water ladder pump. The strength of the Archimedean's Pipe-Screw water pumping concept is possibility to keep the structure simple. Another advantage is its expected low need of maintenance. The present results in practice suggest that the use of Archimedean's Pipe-Screw water pumping Thai sail windmill is advantage other type, which is operated on low wind speed, that it is suitable in Thailand.

\section{CONCLUSION}

From the present study, water discharge was in the range $0.005-0.081 \mathrm{lps}$. It can be seen maximum water discharge of pitch Archimedean's Pipe-Screw (P) is 1.4 $\mathrm{D}$ at $80 \mathrm{rpm}$ for $\alpha=20^{\circ}$ was $0.081 \mathrm{lps}$. These results indicated the pitch of Archimedean's Pipe-Screw the angle slope $(\alpha)$ had affected the water discharge. It was also found that the discharge of the prototype of Thai sail windmill 12B-TSRM coupled to twelve Archimedean's Pipe-Screw pump of wind speed was increased depending on wind speed. The discharge amount varied between $9.56-38.23 \mathrm{~m}^{3} / \mathrm{h}$ at head of 1.5 meters in wind speeds ranging from $1.0-5.0 \mathrm{~m} \mathrm{~s}^{-1}$. It has many advantages despite its relatively moderate efficiency. On other hand; it is simple to design and construct and is also very robust, it is easily repairable and maintainable there would be little need for the services of a technician. All above advantages would help promote our Archimedean's Pipe-Screw for Thai sail wind pump. Water discharge of Archimedean PipeScrews is a function of geometry (angle, pitch of pipe screw and number of rubber tube). Efficiency increases with decreasing average rotating speed. However, would be applying the blades make up of fiber- reinforced polyester in order to there be long life in use in stand of cloth in the future which, it is much more complex than the cloth blades. Therefore, the extra installation costs should be evaluated with the economic gain achieved due to extra Thai Sail windmill for water pumping in the future.

\section{ACKNOWLEDGEMENT}

The researchers are grateful to the National Research Council of Thailand (NRCT) for providing fund in this research work. Thanks are also due to Rajamangala University of Technology Rattanakosin for providing scholarship to the first author for his Ph.D. study program.

\section{REFERENCES}

Ahilan, T., D.K.P. Mohammed and D.S. Arumugham, 2009. A critical review of global wind power generation. Am. J. Applied Sci., 6: 204-213. DOI: 10.3844/ajassp.2009.204.213

Ceccarelli, M., 2014.Contributions of Archimedes on mechanics and design of mechanisms. Mechanism Mach. Theory, 72: 86-93. DOI: 10.1016/j.mechmachtheory.2013.10.005

Chaabene, A.B., M.F. Elkaroui and A. Sellami, 2013. Efficient design of a photovoltaic water pumping and treatment system. Am. J. Eng. Applied Sci., 6: 226-232. DOI: 10.3844/ajeassp.2013.226.232

Major, S., T. Cmmins and S. Noppharatana, 2008. Potential of wind power for Thailand: As assessment. Mj. Int. J. Sci. Tech., 2: 255-266.

Müller, G., 2009. Simplified theory of Archimedean screws. J. Hydraulic Res., 47: 666-669. DOI: 10.3826/j.hr.2009.3475

Pour, M.S., Y. Rashidi and M. Ardestani, 2008. Simulation of wind field in tehran using hybrid diagnostic and prognostic models. Am. J. Environ. Sci., 4: 512-521. DOI: 10.3844/ajessp.2008.512.521

Rojas-Sola, J.I., M. González and E.P. Martín, 2006. Computer-aided design and engineering: A study of windmills in la Mancha (Spain). Renewable Energy, 31: 1471-1482. DOI: $10.1016 /$ j.renene.2006.02.002d 